\title{
Adolescent Girls Empowerment Program (AGEP): Health
}

\author{
Karen Austrian \\ Population Council \\ Erica Soler-Hampejsek \\ Natalie Jackson Hachonda \\ Population Council
}

Paul C. Hewett

Population Council

Follow this and additional works at: https://knowledgecommons.popcouncil.org/departments_sbsr-pgy

Part of the Demography, Population, and Ecology Commons, Family, Life Course, and Society Commons, and the International Public Health Commons How does access to this work benefit you? Let us know!

\section{Recommended Citation}

Austrian, Karen, Erica Soler-Hampejsek, Natalie Jackson Hachonda, and Paul C. Hewett. 2018. "Adolescent Girls Empowerment Program (AGEP): Health," brief. Lusaka: Population Council. 
Social isolation, economic vulnerability, and lack of access to health care and education prevent healthy transitions from childhood to adulthood, especially for adolescent girls in developing countries..$^{1.5}$ In Zambia, poor girls are often at higher risk of gender-based violence and HIV than their male age-mates. ${ }^{6}$ Many girls drop out of school, are unable to find employment, lack the ability to make independent decisions, and are not being reached by existing programs for young people. The root causes of these challenges may reside at the social, community, family, or even at the level of the adolescent girls-whether the reasons are poverty, regressive social and cultural gender norms, or lack of self-esteem on the girls' part. These challenges are interlinked, suggesting that when attempting to shift long-term health outcomes for adolescent girls and young women, the approach should be multisectoral as well.

\section{ADOLESCENT GIRLS EMPOWERMENT PROGRAM (AGEP)}

The AGEP intervention was conducted over two years to support more than 11,000 vulnerable adolescent girls in Zambia. It was led by the Population Council in partnership with the Young Women's Christian Association of Zambia (YWCA), the National Savings and Credit Bank of Zambia (Natsave), and the Government of Zambia. AGEP was based on an asset-building framework that posited that by enhancing girls' social, health, and economic assets in the short term, more positive longer-term dividends would be achieved on sexual health behavior and health outcomes. AGEP was implemented in ten sites within urban and rural areas in four provinces in Zambia. The intervention was comprised of three major components:

1) weekly safe spaces groups in which girls met over the course of two years for training on sexual and reproductive health, life skills, and financial education; 2) a health voucher that girls could use at contracted private and public facilities for general wellness and sexual and reproductive health services; and 3) a savings account that was designed specifically to be girl-friendly. Overall, the participation in the safe spaces groups was low. On average, girls attended about 33 out of 100 sessions, with participation being highest among younger rural girls ( 41 sessions) and lowest among older urban girls ( 26 sessions). About a quarter of girls who were invited to join the program never did, and only about a third participated in more than half of the sessions.

To assess the impact of AGEP on mediating and longer-term demographic, reproductive, and health outcomes, Population Council researchers designed and implemented a longitudinal, cluster randomized controlled trial across all program areas. There were three program versions tested: safe spaces only; safe spaces with health vouchers; and safe spaces with health vouchers and savings accounts, as well as a control group that

\footnotetext{
a In AGEP, "vulnerable" was defined as the number of years a girl was lagging behind in her schooling, relative to her age, taking into account several individual and household factors. See 2016 Population Council brief "Methodology: Reaching the Most Vulnerable Adolescent Girls."
}

The Population Council conducts research and delivers solutions that improve lives around the world. Big ideas supported by evidence:

It's our model for global change. popcouncil.org

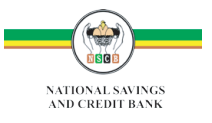




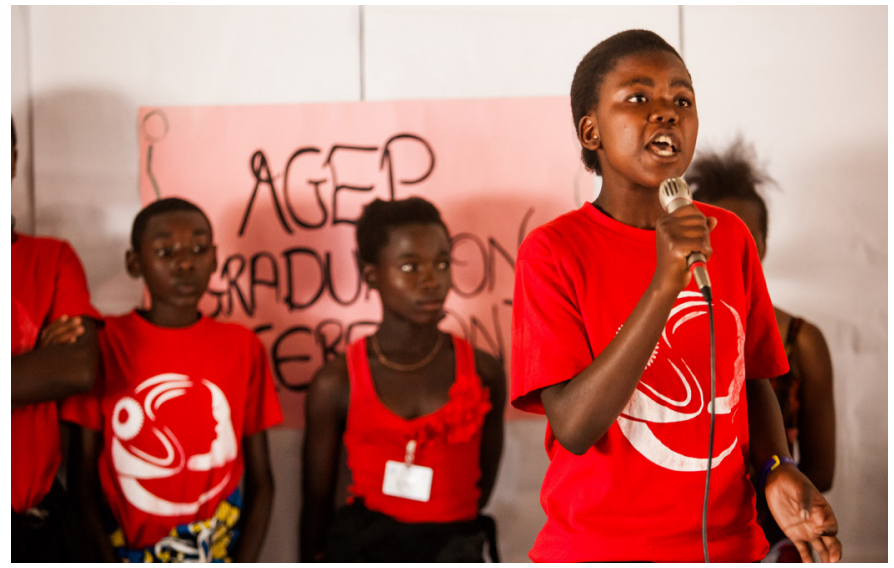

received no program. A baseline survey was conducted in 2013 prior to program implementation and data has been collected annually. A third round of data collection in 2015 produced the midline findings, measuring the program effect immediately at the end of AGEP, and a final round of data was collected in 2017, measuring the effect two years after the end of the program. Our primary analysis looks at all of the girls who were invited to attend the program. However, due to the low participation in the safe spaces groups, we also compare those who actively participated to a portion of the girls who did not receive any program who were similar to those girls in terms of age, household socioeconomic status, parental education, residence, and other measured factors. The focus of this brief is to provide a summary of the health-related effects at the two-year follow-up.

\section{RESULTS}

At the end of the program in 2015, AGEP girls scored almost one point higher on a sexual and reproductive health (SRH) knowledge scale than control girls, and had greater access to safe places in the community apart from home and school. Two years after the program ended, AGEP girls continued to have significantly higher levels of SRH knowledge, but with the closing of the weekly girls' groups they reported that they no longer had as much access to safe places in the community, suggesting that the communities were unable to sustain a dedicated space for girls.

In 2015, AGEP girls did not show significantly higher self-efficacy than control girls. However, two years after the program in 2017, AGEP girls did have significantly higher self-efficacy scores, and this is most true for those who received the full program version with savings accounts. It is possible that as girls age they have more life experiences with which to apply what they learned in AGEP, therefore increasing confidence in their ability to succeed.

In terms of sexual behavior and longer-term reproductive outcomes, at midline AGEP girls who had ever had sex were
- $\quad$ The AGEP intervention aimed to increase health knowledge and self-efficacy through weekly girls' groups meetings, which-together with increased economic assets-would lead to improvements in longer-term improvements in sexual health.

- While the program modestly improved SRH knowledge and self-efficacy, that did not translate into longer-term changes in risky sexual behavior or timing of sexual debut, first birth, and marriage for the full range of adolescent girls eligible to participate in AGEP.

- A small group of select girls who were self-motivated to actively participate in the program showed delays in birth and marriage.

- $\quad$ Programs that seek to improve health outcomes for a wide range of vulnerable adolescents need to address underlying economic and sociocultural constraints to both increase participation and improve the likelihood that the program will result in longer-term health changes.

less likely to have had transactional sex and more likely to have used a condom during their first sexual intercourse. Two years after the program ended, girls who had started having sex prior to the program remained less likely to have transactional sex, however the effect on condom use at first sex was no longer present. When we look at the select group of girls that participated in more than half of the AGEP sessions, compared to the subset of the girls who received no intervention that were similar to the active AGEP girls, the AGEP girls were less likely to have ever given birth or gotten married two years after the program.

\section{CONCLUSION}

The final AGEP findings highlight, in the Zambian context, what can be changed for girls through a girl-level intervention that focuses on building social, health, and economic assets. The program was successfully able to improve SRH knowledge and self-efficacy. The question that AGEP set out to answer was whether medium-term changes in knowledge and self-efficacy combined with changes in gender norms and acceptability of violence would translate into longer-term changes in sexual behavior and timing on initiation of sex, birth, and marriage. For most girls who were eligible to participate in AGEP, the answer is no. For a small group who willingly participated actively, the program was able to delay marriage and birth in the long-term.

The goal, however, is for a program to address the needs of and improve outcomes for a much broader set of vulnerable 
adolescent girls than those who were positively impacted in AGEP. The AGEP interventions focused solely on building assets and skills among the girls, and it is likely that to first attract, and then affect, a broader set of girls, additional interventions are needed to: a) address social and cultural norms on girls' education, rights, and values at the household, school, and community levels, including through engaging boys and men; and b) address the underlying economic constraints in the household that might prevent girls from participating and/or fully benefiting from the program. Perhaps with a more ecological approach that simultaneously engages girls directly, as well as addresses household-level economic constraints and broader social and cultural norms, adolescent girls will have improved longer-term sexual health outcomes.

\section{REFERENCES}

1. Amin, S., L. Rahman, S. Ainul, U. Rob, B. Zaman, and R. Akter. 2010. “Enhancing Adolescent Financial Capabilities through Financial Education in Bangladesh." New York, NY, USA: Population Council.

2. Ashburn, K. and A. Warner. 2010. "Can Economic Empowerment Reduce Vulnerability of Girls and Young Women to HIV? Emerging Insights." Washington, DC, USA: International Center for Research on Women.

3. Dickson, K. and M. Bangpan. 2012. "Providing Access to Economic Assets for Girls and Young Women in Low-andLower Middle Income Countries. A Systematic Review of the Evidence." London: EPPI-Centre, Social Science Research Unit, Institute of Education, University of London.

4. Duflo, E. 2012. "Women empowerment and economic development," Journal of Economic Literature 50(4): 1051-1079.

5. Hallman, K. 2005. "Gendered socioeconomic conditions and HIV risk behaviours among young people in South Africa," African Journal of AIDS Research 4(1): 37-50.

6. Central Statistical Office (CSO), MOH [Zambia], and ICF International. 2014. Zambia Demographic and Health Survey 2013-2014 [Dataset]. Rockville, MD, USA: CSO, $\mathrm{MOH}$, and ICF international.

Authors: Karen Austrian, Erica Soler-Hampejsek, Natalie Jackson Hachonda, and Paul C. Hewett.

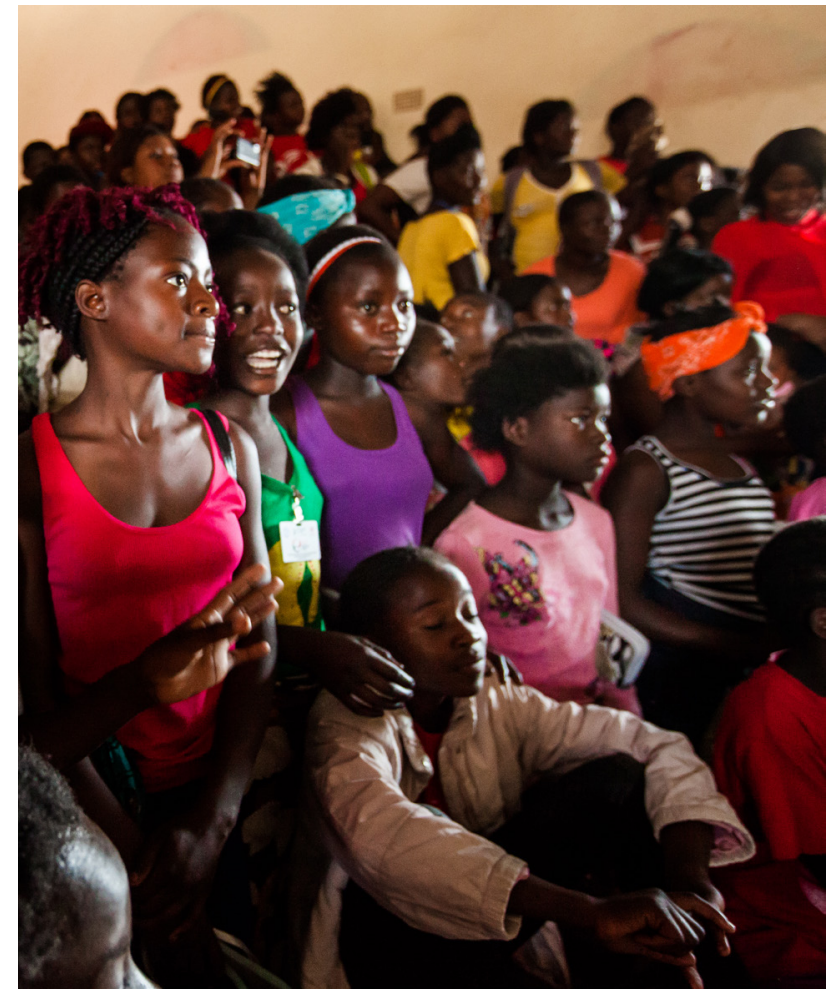




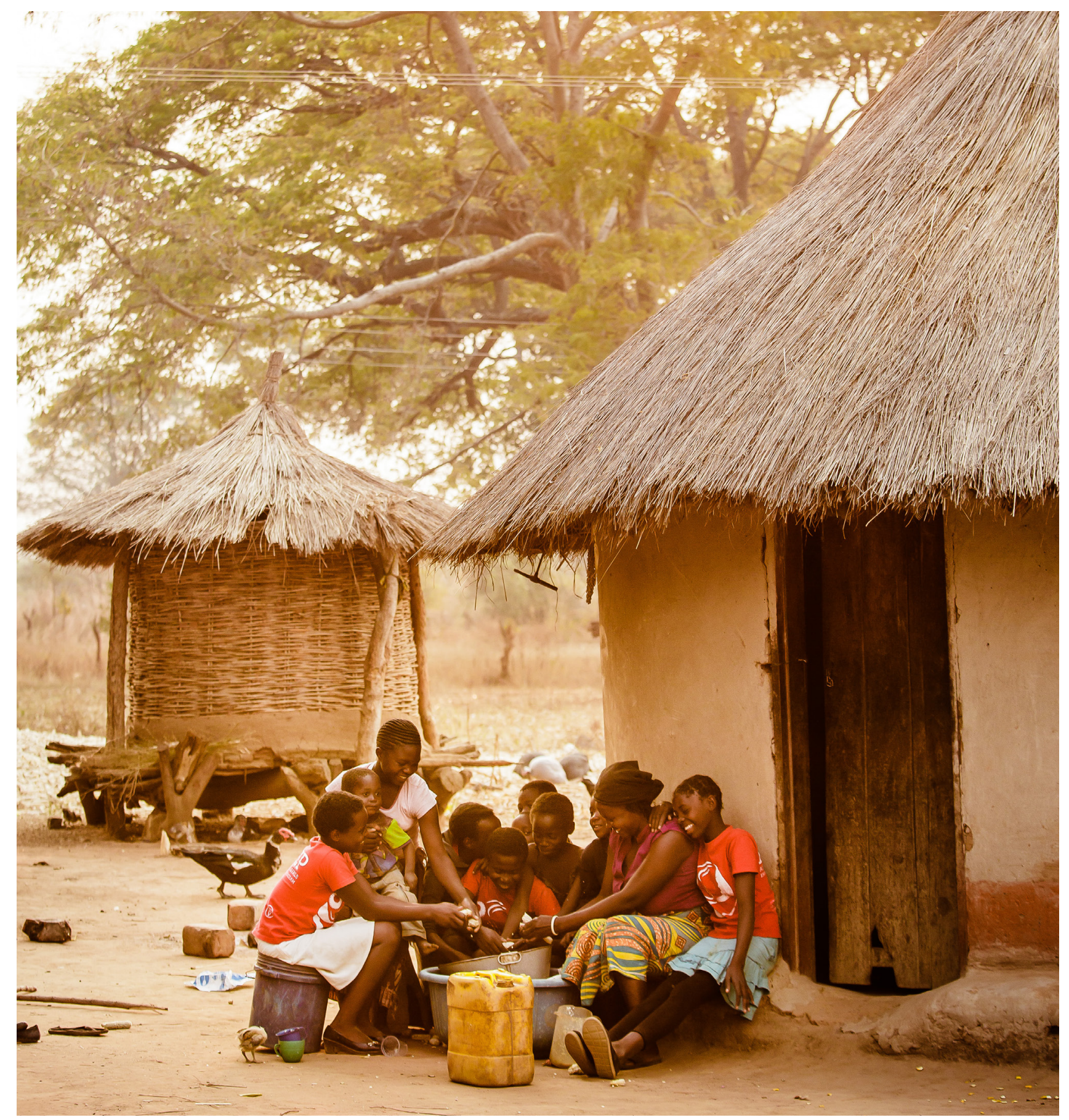

\section{CONTACT INFORMATION}

For more information about AGEP, call +260 211295925

or email: info@popcouncil.org

or visit: http://www.popcouncil.org/research/

adolescent-girls-empowerment-program
Population Council

Plot \#3670 No. 4 Mwaleshi Road

Olympic Park

Lusaka, Zambia 10101 